\title{
High-temperature low cycle fatigue behavior of an equiatomic CoCrFeMnNi high-entropy alloy
}

\author{
Kaiju Lu ${ }^{1 *}$, Ankur Chauhan ${ }^{1 * *}$, Dimitri Litvinov ${ }^{1}$, Mario Walter ${ }^{1}$, Aditya Srinivasan Tirunilai ${ }^{2}$, Jens \\ Freudenberger ${ }^{3,4}$, Alexander Kauffmann ${ }^{2}$, Martin Heilmaier ${ }^{2}$, and Jarir Aktaa ${ }^{1}$ \\ email: *kaiju.lu@kit.edu; $*$ *ankurskchauhan@gmail.com
}

\author{
${ }^{1}$ Institute for Applied Materials, Karlsruhe Institute of Technology (KIT), Hermann-von-Helmholtz-Platz \\ 1, 76344 Eggenstein Leopoldshafen, Germany \\ ${ }^{2}$ Institute for Applied Materials, Karlsruhe Institute of Technology (KIT), Engelbert-Arnold-Strasse 4, \\ 76131 Karlsruhe, Germany \\ ${ }^{3}$ Leibniz Institute for Solid State and Materials Research Dresden (IFW Dresden), Institute for Metallic \\ Materials, D-01069 Dresden, Germany \\ ${ }^{4}$ Institute of Materials Science, Technische Universität Bergakademie Freiberg, 09599 Freiberg, Germany
}

\begin{abstract}
In the present work, low cycle fatigue (LCF) behavior of an equiatomic $\mathrm{CoCrFeMnNi}$ high entropy alloy (HEA) is correlated to the microstructural evolution at $550{ }^{\circ} \mathrm{C}$. The fully reversed strain-controlled fatigue tests were conducted in air under strain amplitudes ranging from 0.2 to $0.8 \%$. The measured cyclic stress response showed three distinct stages which include initial cyclic hardening followed by a quasi-stable cyclic response until failure. The rate and amount of cyclic hardening increased with the increase in strain amplitude. In comparison to common austenitic stainless steels, CoCrFeMnNi HEA shows comparable strength and improved LCF lifetimes at similar testing conditions. Electron-microscopy investigations after failure reveal no noticeable change in grain size, texture and annealing twins density. Initial cyclic hardening is attributed to dislocation multiplication and dislocation-dislocation as well as dislocationsolute atom interaction. The quasi-stable cyclic response is associated with the equilibrium between dislocation multiplication and annihilation, which also leads to the formation of heterogeneous dislocation structures such as ill-defined walls and cells, particularly at higher strain amplitudes. Besides this, the material exhibits serrated plastic-flow due to interactions between mobile dislocations and diffusing solute
\end{abstract}


atoms (such as $\mathrm{Cr}, \mathrm{Mn}$ and $\mathrm{Ni}$ ). Lastly, segregation in the form of Cr- and NiMn-enriched phases were observed near grain boundaries, which appears to have a detrimental effect on the fatigue life.

Key words: High entropy alloy; low cycle fatigue; microstructural evolution; serration; segregation

\section{Introduction}

Conventional alloys based on one or two principal elements, such as aluminum alloys or steels show a trade-off between strength and ductility [1]. The demand for new alloys that offer high strength with excellent ductility has stimulated numerous research activities. During recent years a new class of alloys called high-entropy-alloys (HEAs), consisting of at least five principal elements has been investigated extensively. This alloy design concept provides many options to vary alloy chemistry, and hence, to improve the strength and ductility trade-off [1-4]. At room temperature (RT) for example, the equiatomic CoCrFeMnNi HEA, a faced-centered cubic (FCC) solid solution, first reported by Cantor et al. [2], exhibits an ultimate tensile strength of $\sim 700 \mathrm{MPa}$, ductility of $\sim 50 \%$, fracture toughness values exceeding $200 \mathrm{MPa} \sqrt{ } \mathrm{m}$, as well as high corrosion and oxidation resistance [5-8].

With such superior properties, CoCrFeMnNi HEA could be considered as a potential structural material for certain high-temperature applications [1]. For high-temperature applications, creep properties are of great importance. The $\mathrm{CoCrFeMnNi}$ creep resistance and deformation mechanisms acting at various elevated temperatures were investigated recently $[9,10]$. However, some components in high-temperature applications are generally subjected to repeated thermo-mechanical stresses due to the existence of temperature gradients, especially at the moment of start-ups, shut-downs or during temperature transients, which demands sufficiently competent low cycle fatigue (LCF) properties. LCF behaviors of HEAs have not been studied in depth so far. Only recently, a few studies have concentrated on their LCF behavior but at RT. For instance, Niendorf et al. [11] showed pronounced martensitic transformation upon cycling dualphase $\mathrm{Fe}_{50} \mathrm{Mn}_{30} \mathrm{Co}_{10} \mathrm{Cr}_{10}$ and the appearance of planar slip as well as partial reversibility were assumed to strongly affect the material behavior. Bahadur et al. [12] reported an increase in the intragranular misorientation and dislocation density with increasing strain amplitude. This led to the accumulation of damage and intergranular cracking in equiatomic $\mathrm{CoCuFeMnNi}$ [12]. Moreover, interaction of dislocations with the solute atmosphere, copper-rich nano-clusters and grain boundaries were shown to have retarded slip reversibility, thereby dictating the cyclic deformation behavior [12]. Wang et al. [13] studied LCF cracking behavior of CoCrFeMnNi with three different grain sizes. They found a transition from slip band (SB) cracking to twin boundary (TB) cracking with an increase in the difference in Schmid factors between matrix and twins, which is irrespective of the grain size [13]. Nevertheless, upon reducing 
grain size, they found a slight increase in fatigue life and TB cracking is shown to be promoted due to the reduced SB spacing that facilitates the accumulation and coalescence of defects at TBs and consequently the initiation of TB cracks [13].

Besides, most studies concentrated on investigating the fatigue-crack growth and high cycle fatigue (HCF) behavior of CoCrFeMnNi HEA. For instance, Thurston et al. [14] examined fatigue-crack propagation behavior of CoCrFeMnNi HEA at RT (293 K) and $198 \mathrm{~K}$ and found it comparable to austenitic steels and TWIP steels. They reported that the fatigue threshold, $\Delta K_{\mathrm{TH}}$, increased from $\sim 4.8 \mathrm{MPa} \sqrt{\mathrm{m}}$ to $\sim 6.3 \mathrm{MPa}$ $\sqrt{ } \mathrm{m}$ with a decrease in temperature from $293 \mathrm{~K}$ to $198 \mathrm{~K}$. Moreover, crack paths indicate transition from predominantly transgranular at RT to intergranular-dominant at lower temperature [14]. Kim et al. [15] investigated HCF behavior of $\mathrm{CoCrFeMnNi}$ with a coarse grain size of around $245 \mu \mathrm{m}$ at RT. They found that initially present $\mathrm{Cr}-\mathrm{Mn}$ based oxide phases act as crack sources and deformation twins that uniquely formed at a stress level lower than the critical twining stress provide a crack propagation path [15]. Chlup et al. [16] studied three-point bending HCF behavior of two ultra-fine-grained ( 0.4 and $0.6 \mu \mathrm{m})$ CoCrFeMnNi HEAs. It was revealed that the HEA with the smaller grain size reached slightly better fatigue properties and the formation of nano-twins together with the localized extensive slip activity in abnormally large grains acted as the fatigue crack initiation sites [16]. Furthermore, Tian et al. [17] also reported that the fatigue strength of the CoCrFeMnNi could be ameliorated by refining grain size.

As seen above and to the authors best knowledge, all fatigue studies on CoCrFeMnNi HEA were mostly performed at RT and investigations concerning fatigue behavior at elevated temperatures have not been reported so far. In the present study, LCF behavior of equiatomic $\mathrm{CoCrFeMnNi}$ was investigated at $550{ }^{\circ} \mathrm{C}$. The cyclic stress response and its correlation with the microstructure evolution was examined by employing electron backscatter diffraction (EBSD) and transmission electron microscopy (TEM). Additionally, fracture characteristics were investigated using scanning electron microscopy (SEM).

\section{Material and experimental procedures}

\subsection{Material and its processing}

The investigated equiatomic $\mathrm{CoCrFeMnNi}$ was synthesized using arc melting and drop-casting in an $\mathrm{Ar}$ atmosphere from the high purity elements. The composition (in at. \%) was determined using inductively coupled plasma-optical emission spectrometry (ICP-OES) and was found to be $20.4 \% \mathrm{Co}, 19.7 \% \mathrm{Cr}, 20.3 \%$ $\mathrm{Fe}, 19.2 \% \mathrm{Mn}, 20.4 \% \mathrm{Ni}$, respectively. The as-cast ingots were homogenized at $1200{ }^{\circ} \mathrm{C}$ for $72 \mathrm{~h}$ and subsequently quenched in water. Thereafter, the homogenized material was subjected to cold rotary 
swaging. The LCF specimens were machined out from the cold worked material parallel to the ingots longitudinal direction and finally recrystallized by annealing at $800{ }^{\circ} \mathrm{C}$ for $1 \mathrm{~h}$, leading to a refined isotropic microstructure. Recrystallization post machining prevents surface damage due to the machining process. More details about the processing could be found elsewhere, see Ref. [7].

\subsection{Fatigue testing}

LCF tests were performed on a computer-controlled MTS 810 servo-hydraulic testing machine equipped with a radiative furnace and a high-temperature extensometer (with a gauge length of $7 \mathrm{~mm}$ ). Due to the limited quantity of the material, miniaturized specimen geometry, with a gauge diameter of $2 \mathrm{~mm}$ and a gauge length of $7.6 \mathrm{~mm}$ was used, at an overall length of $27 \mathrm{~mm}$. The strain-controlled tests were carried out at strain amplitudes ranging from 0.2 to $0.8 \%$ under a symmetric triangular waveform and at a nominal strain rate of $3 \times 10^{-3} \mathrm{~s}^{-1}$. All tests were conducted in air at $550{ }^{\circ} \mathrm{C}$. The furnace temperature variation was controlled within $\pm 2 \mathrm{~K}$ by Pt-PtRh thermocouple attached directly to the shoulder of the specimens.

\subsection{Material characterization}

Microstructural characterization was performed before and after deformation using an FEI Nova 200 Dual Beam SEM/FIB equipped with an HKL EBSD detector and an FEI TECNAI-20F TEM equipped with a high-angle annular dark-field (HAADF) detector for scanning TEM (STEM). The post-deformed samples were extracted from the uniform gauge section of failed specimens. For EBSD, pre- and post-deformed samples were mechanically ground (with P600, P1200, P2500 and P4000 SiC emery papers), polished (with 9, 3, $1 \mu \mathrm{m}$ diamond suspensions) and finally vibratory polished (with a $50 \mathrm{~nm}$ colloidal silica suspension). All EBSD scans were acquired at an accelerating voltage of $20 \mathrm{kV}$ and a beam current of 1.7 $\mathrm{nA}$ at a step size of $200 \mathrm{~nm}$. A TSL OIM 8.0 software was utilized for evaluating EBSD data. For TEM, the samples were mechanically ground to $100 \mu \mathrm{m}$ thin foils, and $3 \mathrm{~mm}$ discs were punched out of them. Thereafter, these $3 \mathrm{~mm}$ discs were thinned down to 10 to $20 \mu \mathrm{m}$ by a Gatan dimple grinder and, finally, ion-milled by a Gatan precision ion polishing system (PIPS) to achieve electron transparency. Fracture surface investigations were carried out by employing a Zeiss EVO MA 10 SEM equipped with a Bruker energy dispersive X-ray (EDX) detector. 


\section{Results}

\subsection{Mechanical response}

The mechanical response of a material depends on its processing and testing conditions. The cyclic stress response curves (tensile peak stress versus number of cycles) of the recrystallized $\mathrm{CoCrFeMnNi}$ at $550{ }^{\circ} \mathrm{C}$ are shown in Fig. 1. From Fig. 1a, it is evident that the material's cyclic stress response can be divided into three distinct stages:

Stage 1: Exemplifies rapid cyclic hardening with a rise in the tensile peak stresses for about the first 20 to 120 cycles $\left(N / N_{\mathrm{f}}<0.05\right)$ depending on the applied strain amplitude (see Fig. 1b). As obvious from Fig. 1b, apart from strain amplitudes below $0.4 \%$ where minor or almost no initial hardening was observed, the rate and the amount of cyclic hardening increases with the increase in applied strain amplitude. This initial hardening was determined to be $30 \mathrm{MPa}$ and $55 \mathrm{MPa}$ for $0.4 \%$ and $0.5 \%$ strain amplitudes, respectively. However, for strain amplitudes of $0.75 \%$ and $0.8 \%$ the hardening is estimated to be about $90 \mathrm{MPa}$, indicating an onset of saturation in hardening.

Stage 2: Represents quasi-stable cyclic response (Fig. 1a) with almost no pronounced change in the peak stresses. This stage occupies the majority of the cyclic lifetime $\left(0.05<N / N_{\mathrm{f}}<0.95\right)$.

Stage 3: Governed by fatigue crack initiation and propagation, this stage manifests itself by an initial gradual drop, followed by a rapid drop of the tensile peak stresses until failure. 

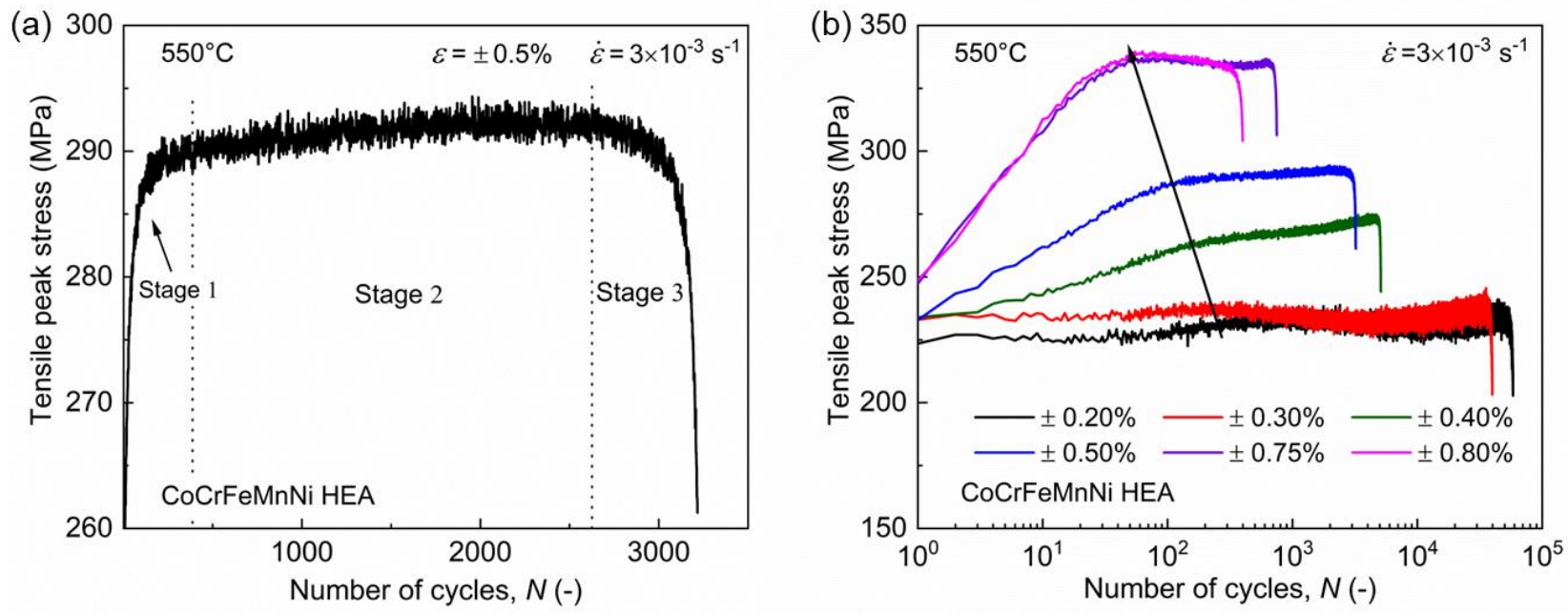

Fig. 1. (a) Tensile peak stress vs. number of cycles plot for CoCrFeMnNi HEA illustrates three distinct stages of the cyclic stress response. (b) Tensile peak stress vs. number of cycles plot shows that the cyclic peak stress as well as the cyclic response is a function of applied strain amplitude.

In addition, the cyclic stress response is also associated to the variation in the inelastic strain. For example, the evolution of symmetrical hysteresis loops over the number of cycles is shown in Fig. 2a. As evident, upon cycling the inelastic strain decreases (the loop width reduces) until it reaches a saturation state (constant loop width). The decrease and the saturation of inelastic strain are linked to the hardening and quasi-stable cyclic response, respectively.

Another interesting phenomenon of discontinuity in plastic flow stress, called serrated flow, can be observed from the hysteresis loops (Fig. 2). As shown in Fig. 2a, the serrated flow occurred in both, the tensile and compression branches of loading regime. Interestingly, the serration magnitude or amplitude appears to decrease progressively with the number of cycles (see Fig. 2b). For example, the serration amplitude decreased continuously from $10 \mathrm{MPa}$ initially to almost naught after some hundred cycles under $0.75 \%$ strain amplitude. 

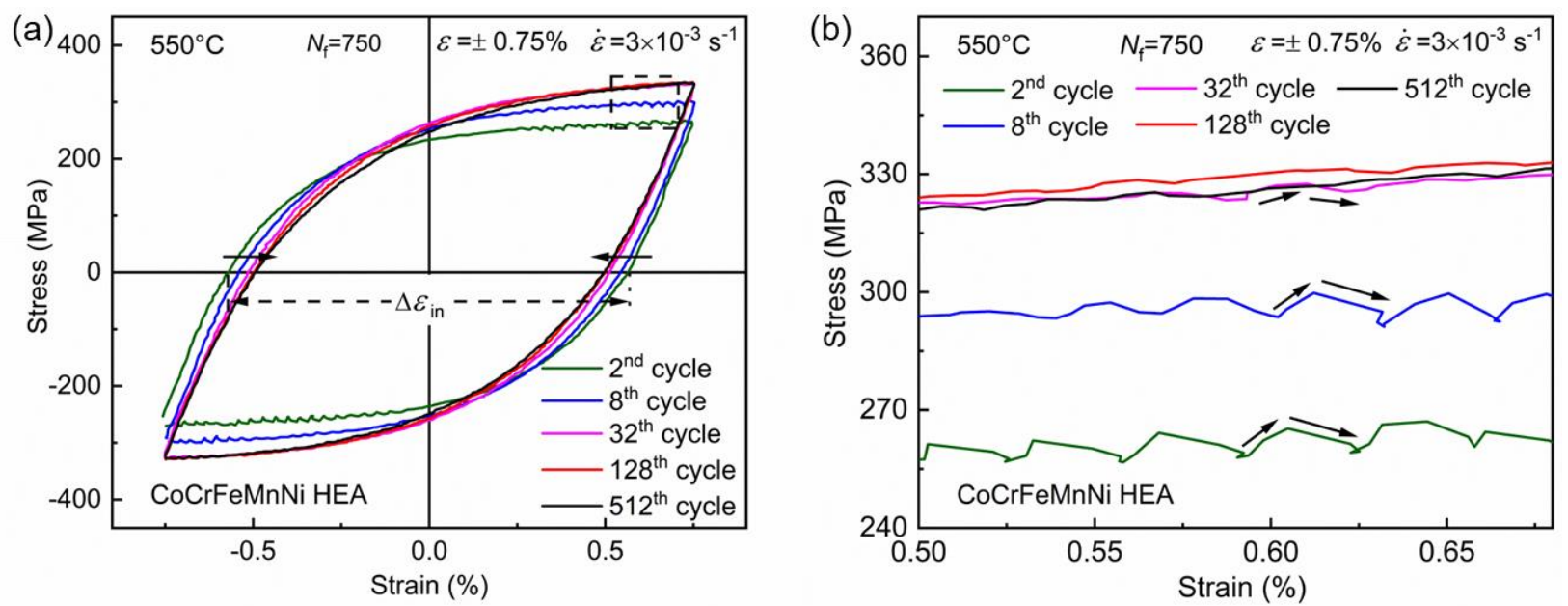

Fig. 2. (a) Hysteresis loops at different numbers of cycles for the sample tested under $0.75 \%$ strain amplitude show the reduction in inelastic strain (loops width reduction) until saturation and serrated flow in both tensile and compression loading regimes. (b) Enlarged view of the inset in (a) shows the progressive decrease of serrated flow with increasing number of cycles.

The summary of LCF tests on CoCrFeMnNi HEA is given in Table 1. Variables such as cyclic stress amplitude $\left(\Delta \sigma_{t} / 2\right)$, inelastic strain amplitude $\left(\Delta \varepsilon_{\text {in }} / 2\right)$ and elastic strain amplitudes $\left(\Delta \varepsilon_{\mathrm{e}} / 2\right)$ were estimated from the saturated hysteresis loops at half-life. While the $\Delta \varepsilon_{\text {in }} / 2$ was determined as the half-width of the saturated hysteresis loops, the $\Delta \varepsilon_{\mathrm{e}} / 2$ was obtained by subtracting $\Delta \varepsilon_{\text {in }} / 2$ from the total strain amplitudes. The lifetime or the number of cycles to failure $\left(N_{\mathrm{f}}\right)$ was defined as the number of cycles at which the peak stress dropped by $10 \%$ of its saturated value.

Table 1. Summary of the LCF tests carried out at $550{ }^{\circ} \mathrm{C}$ on CoCrFeMnNi HEA.

\begin{tabular}{cccccc}
\hline $\begin{array}{c}\text { Total strain } \\
\text { amplitude, } \Delta \varepsilon_{\mathrm{t}} / 2\end{array}$ & $\begin{array}{c}\text { Stress } \\
\text { amplitude*, } \\
\Delta \sigma_{\mathrm{t}} / 2(\mathrm{MPa})\end{array}$ & $\begin{array}{c}\text { Inelastic strain } \\
\text { amplitude* } \\
\Delta \varepsilon_{\text {in }} / 2(\%)\end{array}$ & $\begin{array}{c}\text { Elastic strain } \\
\text { amplitude*, } \\
\Delta \varepsilon_{\mathrm{e}} / 2(\%)\end{array}$ & $\begin{array}{c}\text { Fraction of } \\
\text { inelastic } \\
\text { strain* }\end{array}$ & $\begin{array}{c}\text { Number of } \\
\text { cycles to } \\
\text { failure, } N_{\mathrm{f}}\end{array}$ \\
\hline 0.2 & 232 & 0.04 & 0.16 & $21 \%$ & 58460 \\
0.3 & 266 & 0.12 & 0.19 & $38 \%$ & 39862 \\
0.4 & 272 & 0.20 & 0.20 & $50 \%$ & 5104 \\
0.5 & 291 & 0.29 & 0.21 & $58 \%$ & 3217 \\
\hline
\end{tabular}




\begin{tabular}{llllll}
\hline 0.75 & 328 & 0.50 & 0.26 & $66 \%$ & 750 \\
0.8 & 330 & 0.55 & 0.25 & $68 \%$ & 400
\end{tabular}

* Measured at half-life.

During LCF, cyclic stress amplitude $\left(\Delta \sigma_{t} / 2\right)$ has been shown to follow a power type relation with the inelastic strain amplitude $\left(\Delta \varepsilon_{\text {in }} / 2\right)[18]$ which is written as:

$$
\Delta \sigma_{\mathrm{t}} / 2=K\left(\Delta \varepsilon_{\mathrm{in}} / 2\right)^{n}
$$

where $K$ is the cyclic strain hardening coefficient and $n$ is the cyclic hardening exponent. The bilogarithmic plot of the stress amplitude $\left(\Delta \sigma_{t} / 2\right)$ versus inelastic strain amplitude $\left(\Delta \varepsilon_{\text {in }} / 2\right)$ obtained from the LCF data at different strain amplitudes is shown in Fig. 3a. As evident, the data points exhibit a linear trend. The values of parameters $K$ and $n$ obtained from the linear fit of this data with Eq. (1) are shown in Fig. 3a and also listed in Table 2. Furthermore, upon comparison with other common FCC steels (e.g. 1515Ti, 304 and 316Ti austenitic stainless steels (SS) [19-21]), CoCrFeMnNi HEA exhibits comparble cyclic strength at investigated testing conditions (see Fig. 3a).
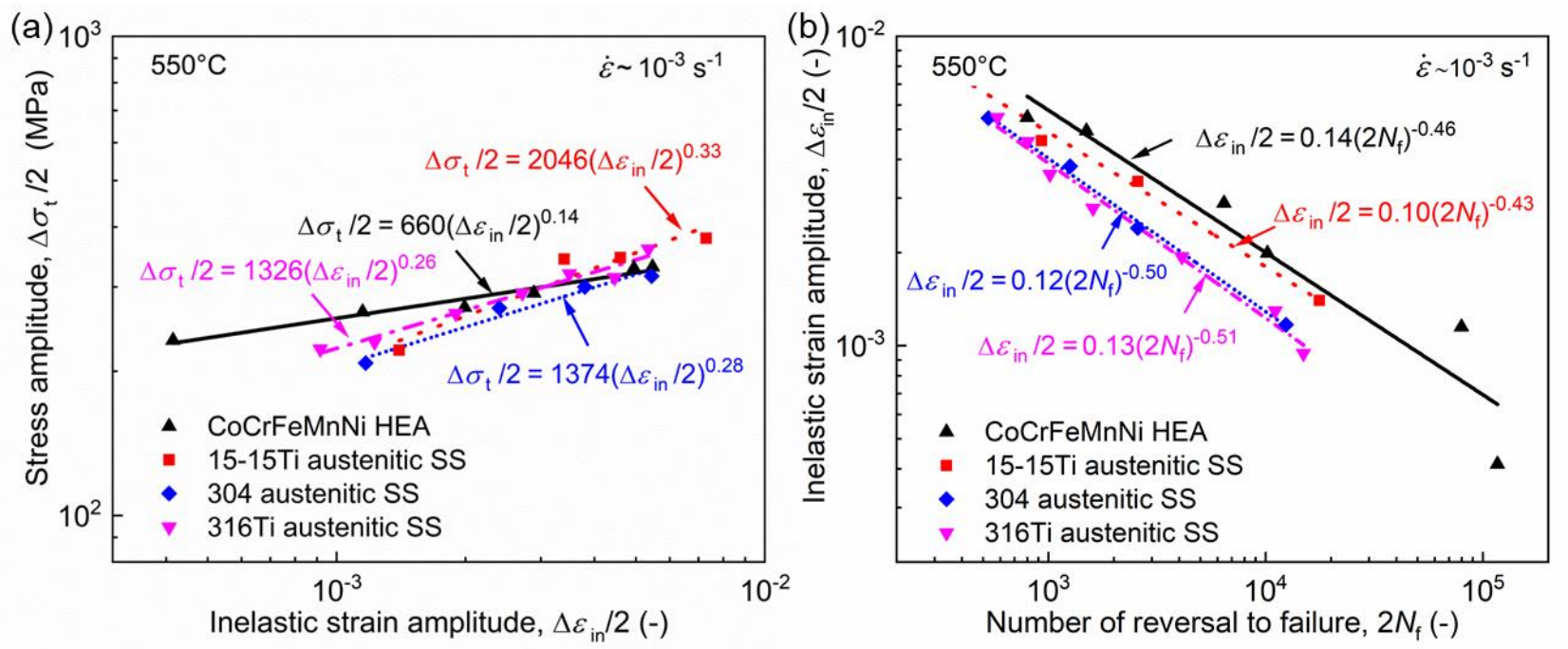

Fig. 3. Bilogarithmic plot of (a) the stress amplitude $\left(\Delta \sigma_{t} / 2\right)$ versus inelastic strain amplitude $\left(\Delta \varepsilon_{\text {in }} / 2\right)$ and (b) the inelastic strain amplitude $\left(\Delta \varepsilon_{\text {in }} / 2\right)$ versus number of reversals to failure $\left(2 N_{\mathrm{f}}\right)$ obtained from the LCF data of CoCrFeMnNi and other FCC steels (e.g. 15-15Ti, 304 and 316Ti austenitic stainless steels [19-21]) under different strain amplitudes and fitted linearly with Eq. (1) and (2), respectively. 
It is clear from Table 1 that fatigue life decreases with an increase in applied strain amplitude. In the LCF regime, the cyclic lifetime is mainly determined by inelastic strain [22], whose fraction increases from $21 \%$ at the lowest tested strain amplitude to $68 \%$ at the highest one. The inelastic strain amplitude has also been shown to follow a power type relation with the number of reversals to failure $\left(2 N_{\mathrm{f}}\right)$, which is known as Coffin-Manson model [23, 24]:

$$
\Delta \varepsilon_{\mathrm{in}} / 2=\varepsilon_{\mathrm{f}}^{\prime}\left(2 N_{\mathrm{f}}\right)^{c}
$$

where $\varepsilon_{\mathrm{f}}^{\prime}$ is the fatigue ductility coefficient defined as the strain intercept at $2 N_{f}=1$ and $c$ is the fatigue ductility exponent. The bilogarithmic plot of $\Delta \varepsilon_{\text {in }} / 2$ versus $2 N_{\mathrm{f}}$ fitted with Eq. (2) is shown in Fig. 3 b. It is evident that in the LCF regime the fatigue lives of $\mathrm{CoCrFeMnNi}$ can be accurately predicted by using the Coffin-Manson model. The values of LCF parameters $\left(\varepsilon_{\mathrm{f}}^{\prime}\right.$ and $\left.c\right)$ determined from the linear fit of the experimental data are listed in Table 2. Furthermore, upon comparison with other common FCC steels [19-21], CoCrFeMnNi HEA exhibits a longer lifetime at similar inelastic strain amplitudes, indicating a better inelastic-strain resistance (see Fig. 3b).

Table 2. Values of the parameters obtained from the analysis of the LCF data.

\begin{tabular}{lccccc}
\hline Material & $\begin{array}{c}\text { Elastic } \\
\text { modulus, } E \\
(\mathrm{GPa})\end{array}$ & $\begin{array}{c}\text { Cyclic strain } \\
\text { hardening } \\
\text { coefficient, } K \\
(\mathrm{MPa})\end{array}$ & $\begin{array}{c}\text { Cyclic strain } \\
\text { exponent, } n\end{array}$ & $\begin{array}{c}\text { Fatigue ductility } \\
\text { coefficient, } \varepsilon_{\mathrm{f}}^{\prime}\end{array}$ & $\begin{array}{c}\text { Fatigue } \\
\text { ductility } \\
\text { exponent, } c\end{array}$ \\
\hline CoCrFeMnNi & 155 & 660 & 0.14 & 0.14 & -0.46 \\
\hline
\end{tabular}

\subsection{Microstructural investigations}

In order to understand the active deformation mechanisms, microstructural investigations were carried out before and after cyclic straining and are presented in the following subsections.

\subsubsection{Before cyclic straining}

The initial representative microstructure of the recrystallized material, characterized via EBSD and TEM, is shown in Fig. 4a and Fig. 5a. The inverse pole figure (IPF) map acquired along loading direction (LD) via EBSD in Fig. 4a shows that the grains manifest random orientation. The majority of the grain boundaries $(\sim 96 \%)$ have a misorientation greater than $15^{\circ}$ (i.e. they are high angle grain boundaries 
(HAGBs)). These observations suggest a fully recrystallized microstructure, which has almost no dislocations (see Fig. 5a). Additionally, the material exhibits a significant density of annealing twins (see Fig. 4a and Fig. 5a), covering an area fraction of about 35\%, due to its low stacking fault energy (SFE) [6$8,25]$. The average grain size was determined to be $\sim 6.4 \mu \mathrm{m}$ via EBSD.

\subsubsection{After cyclic straining}

The orientation maps acquired via EBSD after cyclic straining at $550^{\circ} \mathrm{C}$ under two different strain amplitudes are shown in Fig. 4b-c. Various material related informations including average grain size, twins and grain boundary fractions are listed in Table 3. Upon comparison with the undeformed state, it is evident that the material after cycling shows no prominent change in its texture, i.e. the grains still manifest random orientations (see Fig. 4a-c). Additionally, no noticable change in the grains size (including twins) and twin fraction was seen (see Table 3). Nevertheless, there is a noticeable change in the grain boundary fractions: The fraction of low angle grain boundaries (LAGBs), having misorientation lower than $15^{\circ}$, increased upon cycling and with an increase in applied strain amplitude (see Table 3). This indicates that upon cycling dislocations sub-grain structures are formed and their density increased with an increase in applied strain amplitude. 

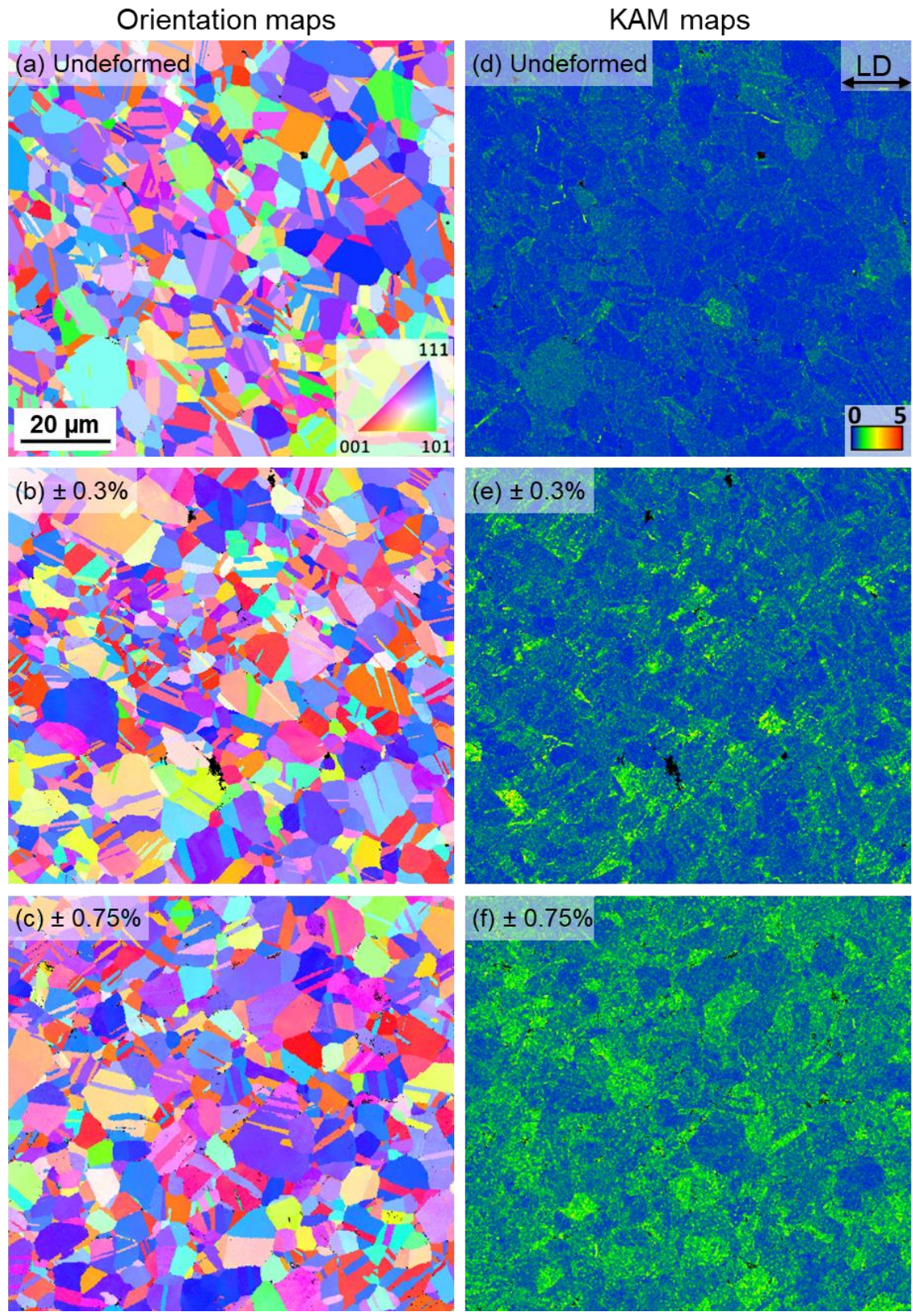

Fig. 4. (a-c) Inverse pole figure orientation parallel to loading direction (LD) and (d-f) Kernel average misorientation (KAM) maps obtained by analyzing EBSD scans taken before (undeformed) and after cyclic deformation under $0.3 \%$ and $0.75 \%$ strain amplitudes at $550{ }^{\circ} \mathrm{C}$. Orientation maps show no noticeable change in grain size, texture and twins area fraction upon cycling. However, KAM maps show an increment in KAM which further increased with increasing applied strain amplitude. Color keys and scale bar are provided as insets in (a) and (d), respectively, are valid for each type of maps. 
Table 3. Average grain size, twins area, HAGBs, and LAGBs fractions measured via EBSD before and after cycling under various strain amplitudes at $550{ }^{\circ} \mathrm{C}$.

\begin{tabular}{ccccc}
\hline Condition & Average grain size $(\mu \mathrm{m})$ & $\begin{array}{c}\text { Twins area } \\
\text { fraction }\end{array}$ & $\begin{array}{c}\text { HAGBs } \\
\text { fraction }\left(>15^{\circ}\right)\end{array}$ & $\begin{array}{c}\text { LAGBs } \\
\text { fraction }\left(<15^{\circ}\right)\end{array}$ \\
\hline Undeformed & 6.4 & $35 \%$ & 0.96 & 0.04 \\
$0.3 \%$ & 6.7 & $34 \%$ & 0.88 & 0.12 \\
$0.5 \%$ & 6.5 & $34 \%$ & 0.86 & 0.14 \\
$0.75 \%$ & 6.4 & $36 \%$ & 0.82 & 0.18 \\
\hline
\end{tabular}

In order to understand, in which additional form inelastic strain accumulates during cyclic straining, the intragranular misorientation was evaluated using kernel average misorientation (KAM). In KAM, the average misorientation between a point and its neighboring points (up to 1st nearest neighbors) was calculated. The kernel exclusion criterion which excludes points with misorientation exceeding $5^{\circ}$ was applied during this estimation. The calculated values can be visualized either in the form of a color-coded map (see Fig. 4d-f) or as a graph (see Fig. 6). As KAM considers only misorientations in a small local neighborhood within a grain, it also provides a good estimation of the local geometrically necessary dislocation (GND) density [26]. Higher KAM values correspond to higher local misorientations (i.e. higher inelastic strain accumulation) and vice versa. Upon comparing KAM maps before and after cyclic straining (Fig. 4d-e), a noticeable gain in the green color, representing high KAM, is evident after cycling. This exaggerates further and becomes even more uniform with the increase in the applied strain amplitude (Fig. 4f). Here, high KAM suggest a presence of the high dislocation density. Similar observations can also be realized from the KAM distribution plots, shown in Fig. 6. Clearly, upon cycling, the KAM distribution spread widens with a coexisting peak-shift towards higher values. This suggests that inelastic strain accumulates during cycling by an increment in the dislocation density, which increases further with increase in applied strain amplitude. 

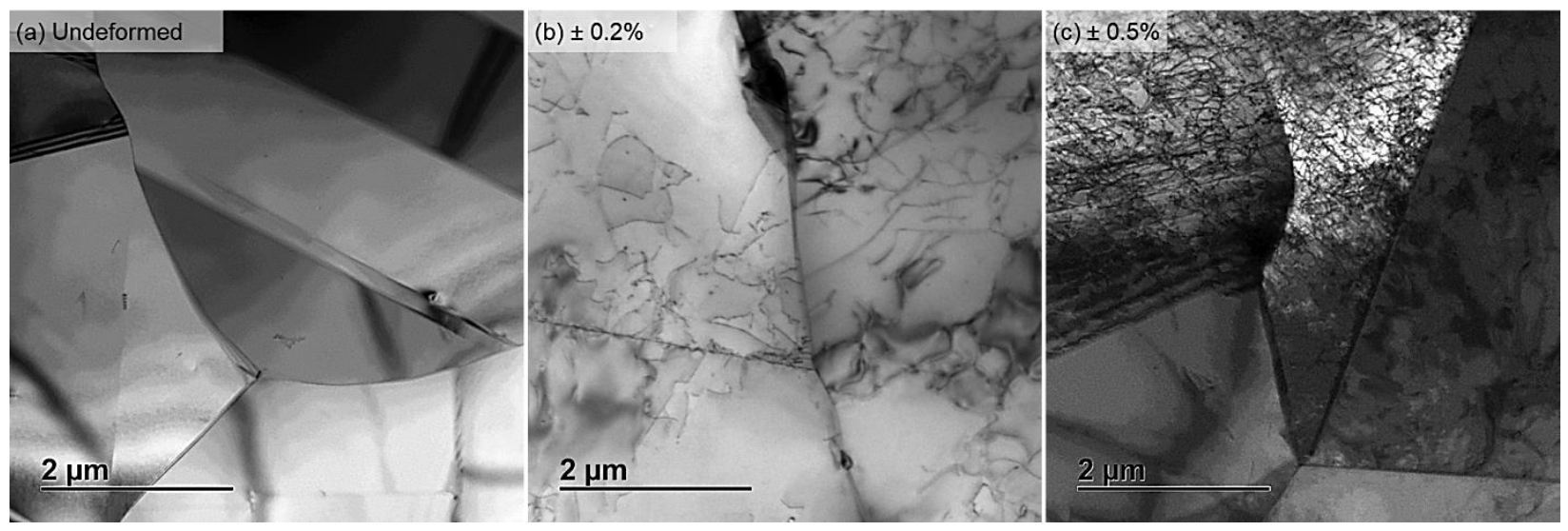

Fig. 5. Representative TEM micrographs taken before (undeformed) and after cyclic straining under strain amplitude of $0.2 \%$ and $0.5 \%$ at $550{ }^{\circ} \mathrm{C}$. (a) Undeformed microstructure manifests twins and almost no dislocations. (b-c) In general, deformed microstructure exhibits comparatively high dislocation density that varies from grain to grain and with applied strain amplitude (i.e. dislocation density increases with increasing applied strain amplitude).

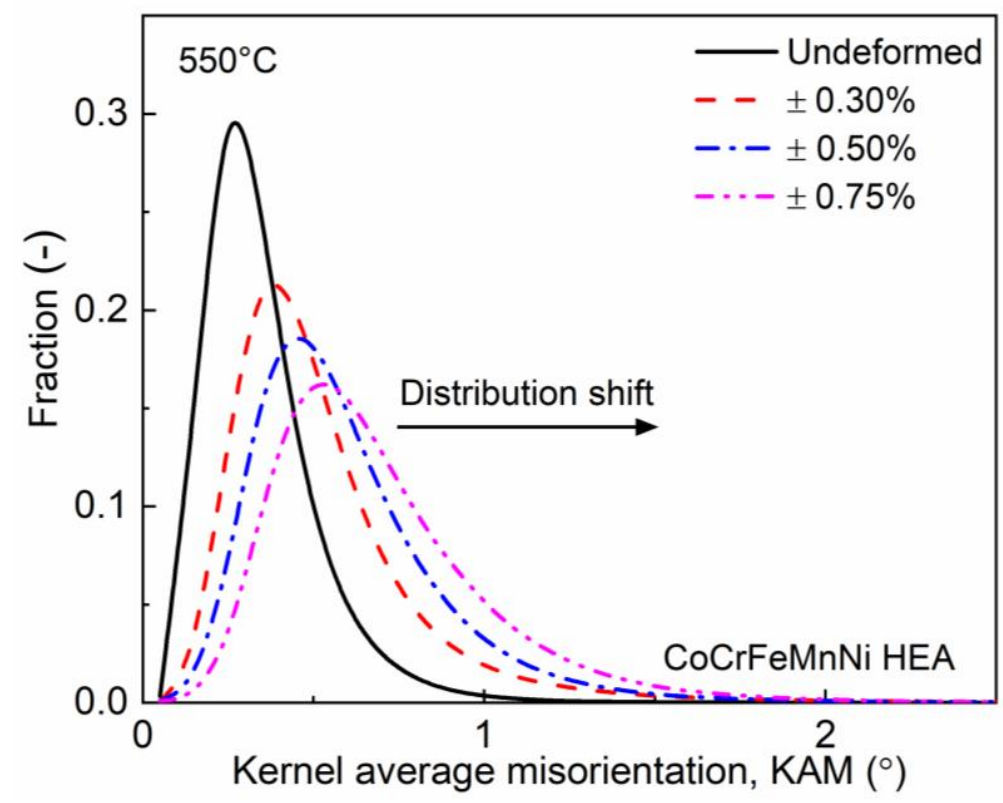

Fig. 6. KAM distribution plots obtained by analyzing EBSD scans taken before (undeformed) and after cyclic straining under various strain amplitudes at $550{ }^{\circ} \mathrm{C}$. KAM distribution spread progressively widens and its peak shifts towards higher values upon cycling and with increase in applied strain amplitude.

In order to delineate microstructural evolution at even higher resolution and to confirm EBSD results, TEM investigations were carried out. As evident, in an undeformed state the material manifests low 
dislocation density (see Fig. 5a). In contrast, the cycled specimens exhibit comparatively high dislocation densities, depending upon applied strain amplitude, confirming EBSD results (see Fig. 5b-c, Fig. 7 and Fig. 8). Interestingly, grains manifest distinct dislocation structures depending on the extent of deformation and their orientation. In general, at lower strain amplitudes, dislocation density is low and varies both within and from grain to grain (Fig. 5b and Fig. 7). Here, various distinct dislocation structures can be observed. For example, Fig. 7a-b presents dislocations arrays of planar slip in the form of pile-ups at grain boundaries and bands inside grains. Besides, grains mostly manifest discrete dislocation segments, that appear to have undergone jerky motion, including dislocations looping (Fig. 7a-c). Few grains also reveal high density of dislocations, forming entanglements with remnant slip traces (see Fig. 7d). At higher strain amplitudes, the density of dislocations is comparatively high in most grains and more heterogeneous dislocation structures, including walls (see Fig. 8a) and few ill-defined cells (see Fig. 8b) are observed. Here, the regions with lower and higher dislocation densities correspond to those with low and high KAM values, respectively.

After cycling, another striking observation is the segregation of alloying elements near grain boundaries in the form of blocky and faceted sub-micron sized precipitates (see marked secondary-phases in Fig. 8a and Fig. 9a). Thorough investigation of the undeformed state, revealed no sign of such segregation. Based on the chemical analysis, these precipitates are found to be of two types: 1) Cr-enriched and 2) NiMnenriched (see EDX elemental maps in Fig. 9). Additionally, the segregation volume fraction was found to be higher at smaller strain amplitudes, as these tests led to longer temperature exposure (the fatigue tests lasted from about 1 to 47 hours for strain amplitudes ranging from 0.8 to $0.2 \%$ ). 

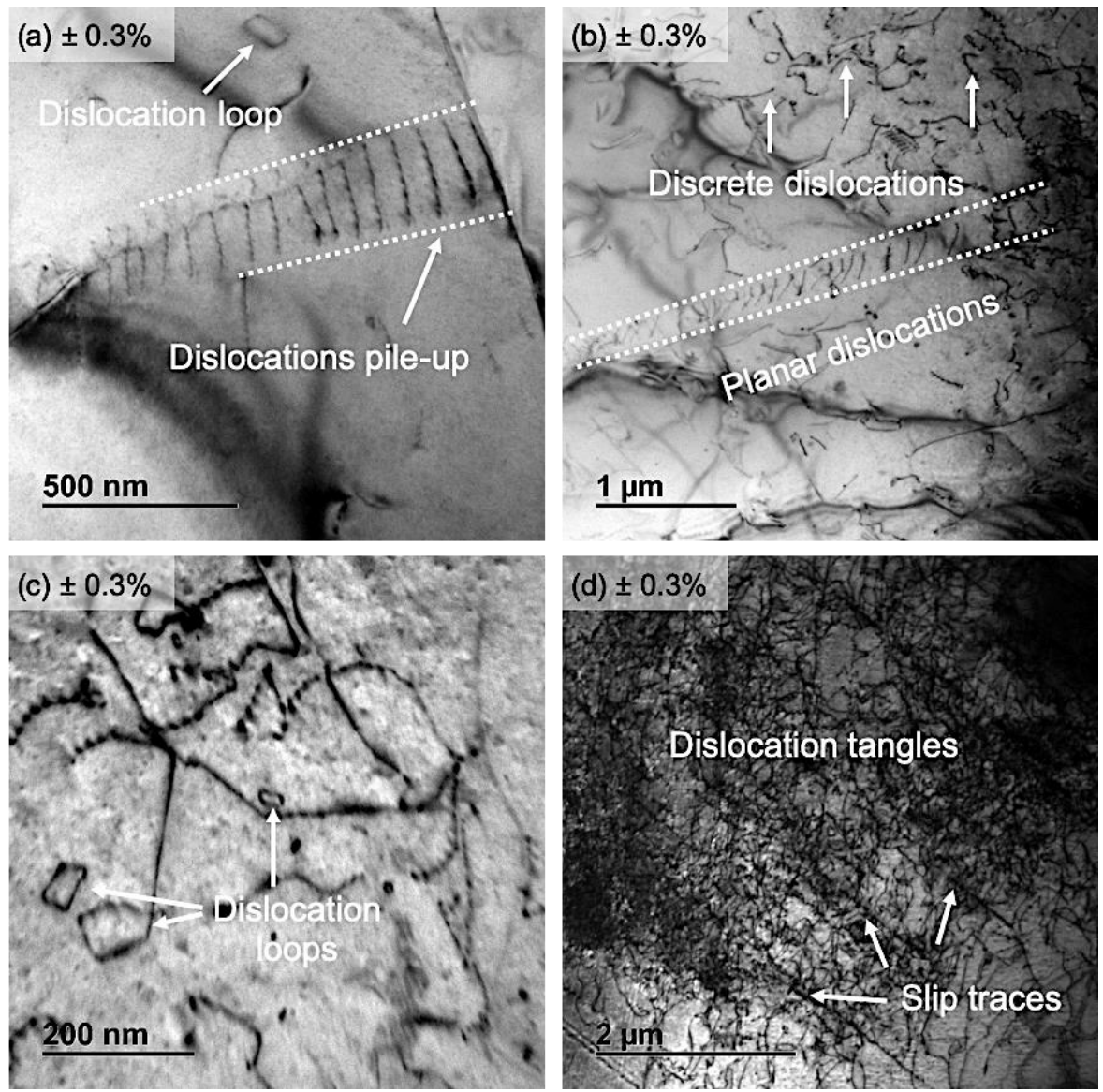

Fig. 7. TEM micrographs taken after cyclic straining under a strain amplitude of $0.3 \%$ at $550{ }^{\circ} \mathrm{C}$. At lower strain amplitudes, density of dislocations varied both within and from grain to grain. Various distinct dislocation structures were observed that include (a) dislocations pile-up at grain boundaries, (b) planar slip band, (a, b, c) discreet dislocations, that appear to have undergone jerky motion, along with dislocation loops, and (d) dislocation entanglements along with remnant slip traces. 

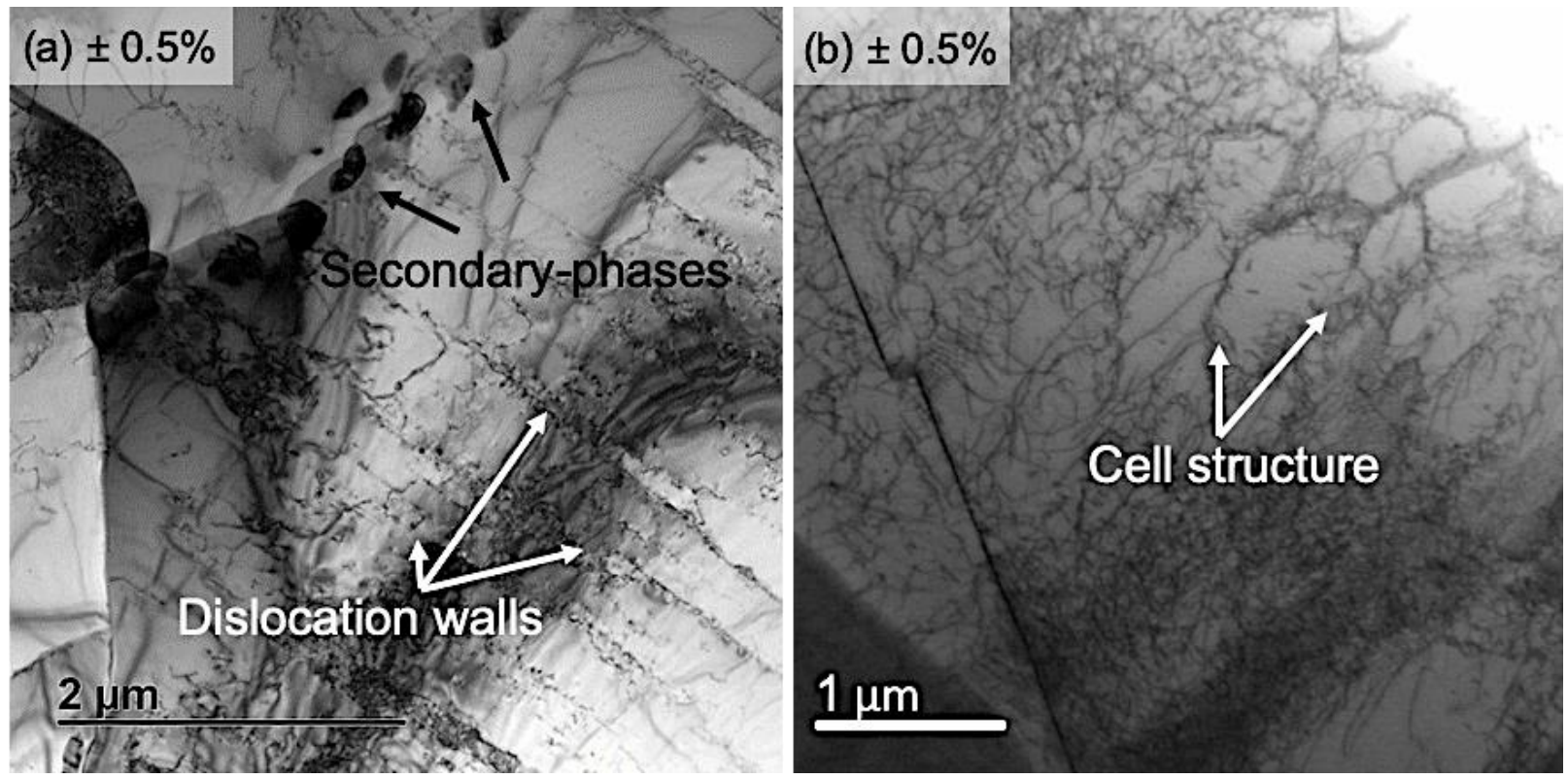

Fig. 8. TEM (a) and HAADF-STEM (b) micrographs taken after cyclic straining under a strain amplitude of $0.5 \%$ at $550{ }^{\circ} \mathrm{C}$. At higher strain amplitudes, more uniform dislocation density was observed in almost all grains. (a) Shows dislocations aligned in straight walls and secondary phases formed as a result of segregation at grain boundaries and (b) presents ill-defined dislocations cell structures. 

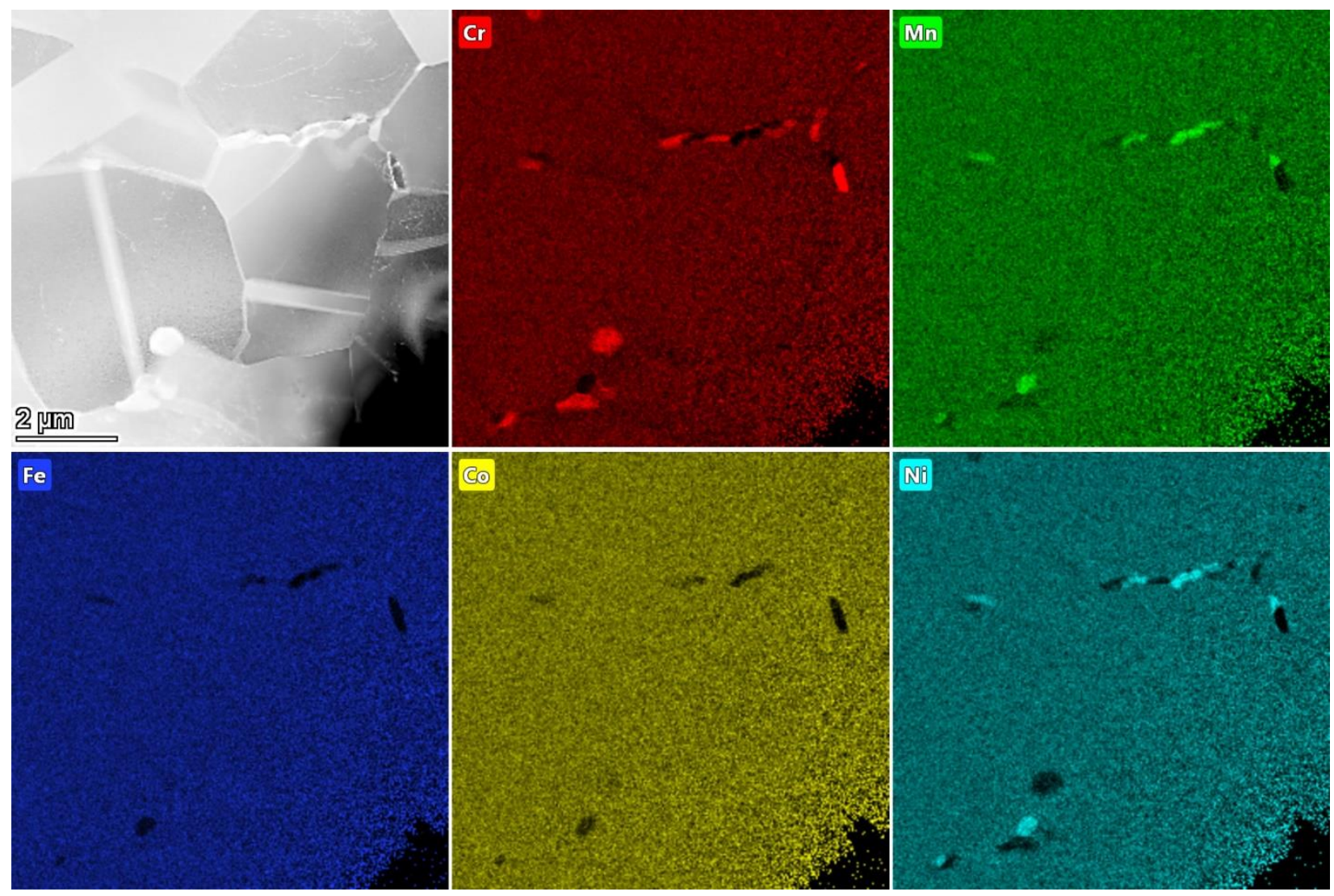

Fig. 9. HAADF-STEM micrograph along with its corresponding EDX maps show two kinds of segregation at grain boundaries: 1) Cr-enriched and 2) NiMn-enriched in the sample tested under a strain amplitude of $0.5 \%$ at $550{ }^{\circ} \mathrm{C}$.

\subsection{Fracture characteristics}

In order to investigate fracture surfaces, the fatigue cracked specimens were broken at RT. The representative fracture surface characteristics of a particular failed specimen are as shown in Fig. 10. Fig. 10a presents an overall view of the fracture surface with marked crack initiation site, stable crack growth region and final rupture region. As typical, the fatigue cracks initiated at the specimen surface (Fig. 10b), and their density increased with the increase in applied strain amplitude. The stable crack growth region manifests transgranular ductile fracture features called striations (see Fig. 10c), formed as a result of repeated crack blunting and sharpening process [22]. Here, the average striation spacing increased with the increase in both strain amplitude and the distance from the initiation site (not shown here), indicating an increase in crack growth rate. Additionally, the secondary cracks that formed near the crack initiation site (see Fig. 10d), appear to have influenced the main crack propagation path. Furthermore, the fracture surface reveals several embedded particles of diameter up to few micrometers (indicated by black arrows 
in Fig. 10c). These particles were identified by EDX analysis to be $\mathrm{Cr}-\mathrm{O}$ enriched (see EDX elemental maps in Fig. 10e) and could both have initiated cracks and affected their propagation path. It is noteworthy that these particles are different than those (Cr-enriched phase mentioned above) precipitated during testing, as they were already present in the initial undeformed microstructure (not shown here). In addition, oxide layer was observed on both specimen and fracture surfaces, especially near crack initiation sites (not shown here). This in-situ oxidation is also known to assist both crack initiation and its propagation [27-29].
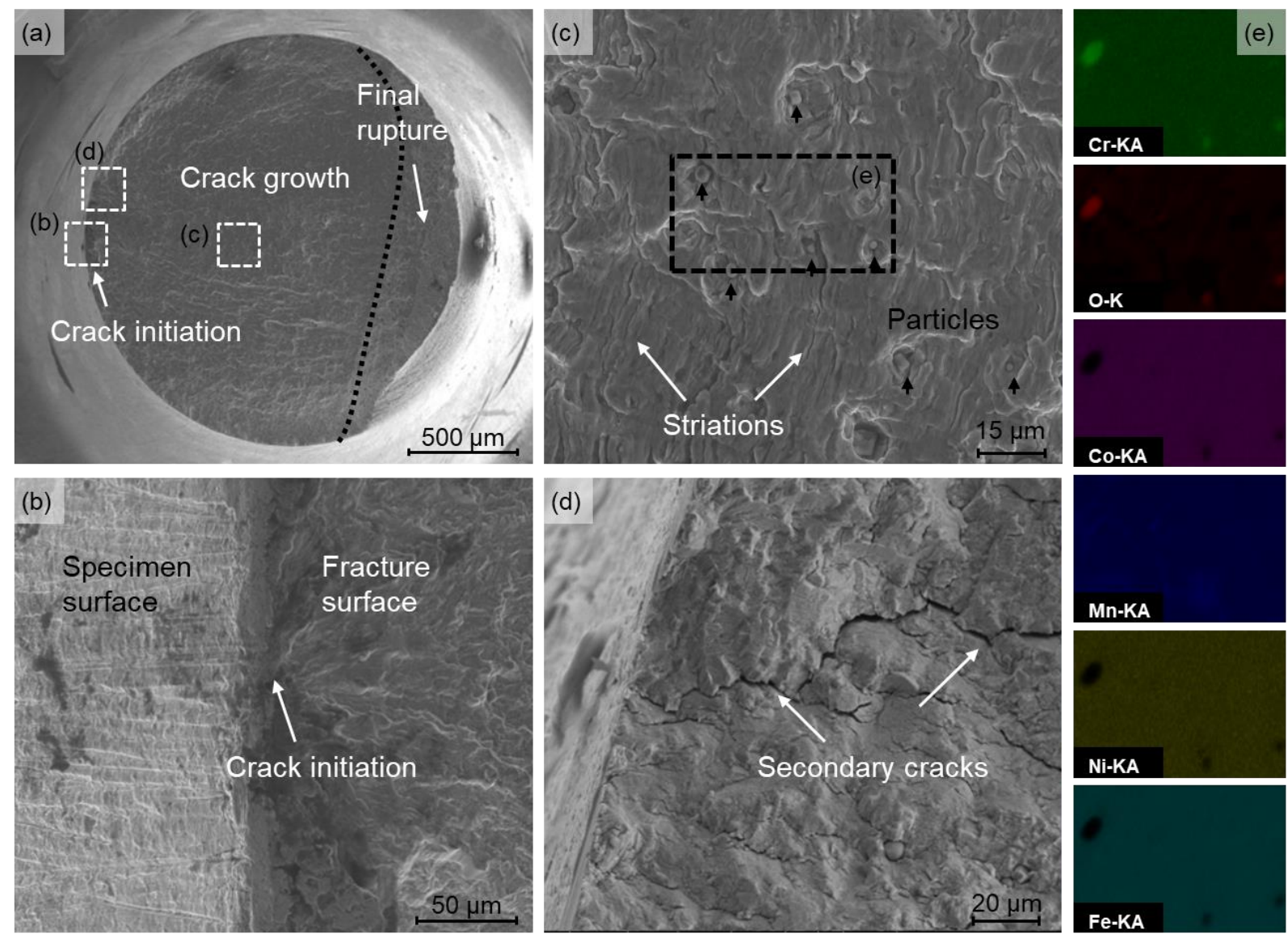

Fig. 10. SEM fracture surface micrographs of the sample tested under $\pm 0.3 \%$ strain amplitude shows (a) overall view of the fracture surface, (b) enlarged crack initiation site near specimen surface, (c) stable crack growth region showing transgranular ductile fatigue fracture features called striations and embedded particles of about few micrometers, (d) secondary cracks and (e) EDX elemental maps acquired for the selected region in (c) show embedded particles to be $\mathrm{Cr}-\mathrm{O}$ enriched. 


\section{Discussion}

\subsection{Microstructural evolution and mechanical response}

As previously mentioned, the overall texture, grain size and annealing twin density remained stable after cycling CoCrFeMnNi HEA. However, the main difference was observed with respect to the increment in dislocation density (see Fig. 5). This is in accordance with the CoCrFeMnNi SFE (> $30 \mathrm{~mJ} / \mathrm{m}^{2}$ ) at hightemperatures which supports slip dominated mechanisms [30]. During initial cycling, dislocations nucleate, multiply and interact with themselves as well as with the solute atoms, which contributes to the observed initial hardening. Moreover, the dislocation evolution also leads to the change in the average local misorientation, which is a function of strain amplitude and is consistent with the amount of cyclic hardening. In general, at lower strain amplitudes, a low non-uniform density of discrete dislocations was observed (see Fig. 5b, Fig. 7a-c ). Whereas, at higher strain amplitudes, a comparatively higher density of interacting dislocations was observed. This resulted in comparatively higher cyclic hardening under higher strain amplitudes. Similar initial hardening behavior has also been reported before for other materials, see for example Refs. [31-35]. Various distinct dislocation structures such as pile-ups, planar slip bands, dislocation loops and entanglements including cell structures were observed upon cycling (see Fig. 7 and Fig. 8). Dislocation structures like pile-ups and planar slip bands are usually associated to the planar movement of dislocations due to the low SFE [34]. Dislocations loops can also result from the movement of superjogs and multiple co-planar slip activity [36]. Nevertheless, due to the constrains and for continuous deformation, dislocations in some grains can also glide along secondary slip systems and then cross-slip [37]. The resulting wavy-slip leads to the formation of complex structures, e.g. tangled structures (see Fig. 7d). As the incidence of tangled structures increases with increasing dislocation density, they could act as barrier for dislocation motion which further promote activation of secondary slip systems and cross-slip [34, 38]. The activation of secondary slip systems facilitates interactions between dislocations which are responsible for the formation of dense dislocation regions, i.e. dislocation walls (see Fig. 8a). At elevated temperatures, edge and screw dislocations are known to climb and easily crossslip, respectively, which contributes to dynamic recovery or annihilation processes. The dynamic equilibrium between dislocation multiplication and annihilation leads to a quasi-stable density of dislocations; and thus, resulting in a quasi-stable cyclic response. Here, dislocations rearrange themselves into more stable lower-energy configurations, such as the observed ill-defined cell structures [39-43] (see Fig. 8b). These structures manifest both high and low dislocation density regions and were mostly observed at higher applied strain amplitudes. Finally, with relatively minor microstructural changes in the 
following cycles, fatigue crack initiation and propagation leads to a gradual and then rapid drop of the peak stresses until failure.

Additionally, as seen in Fig. 3b, CoCrFeMnNi shows better inelastic-strain resistance in comparison to the common coarse-grained FCC steels ( 65 - $75 \mu \mathrm{m}$ grain size for 15-15 Ti and 304 austenitic SS) [19-21]. This could be due to the suppressed strain localization in the investigated HEA. In contrast to the referenced coarse-grained FCC steels, where typical fatigue dislocation structures (e.g. cells, ladder, vein, labyrinth, and persistent slip bands) are commonly observed, CoCrFeMnNi exhibits only limited illdefined cell structures. One possible reason could be an effect of its smaller grain size $(\sim 6.4 \mu \mathrm{m})$, since these structures require some minimum volume for their creation [44] and are linked to the formation of extrusions and intrusions, where fatigue cracks are known to nucleate [45]. Yamaguchi et al. [46] reported that the high-temperature fatigue life of the austenitic steels decreases with increasing grain size. This was also linked to the formation of dislocation cell structures in the steels with larger grain sizes. The detailed grain size effect on the HEA fatigue life still needs further investigations. Furthermore, $\mathrm{CoCrFeMnNi}$ relatively low SFE and severely distorted lattice [47] could also retard massive cross-slip of dislocations, which could inhibit strain localization.

\subsection{Segregation}

Another noticeable observation upon cycling is the segregation of alloying elements in the form of $\mathrm{Cr}$ enriched and NiMn-enriched precipitates near grain boundaries (see, Fig. 8a and Fig. 9). The phase stability of $\mathrm{CoCrFeMnNi}$ is reported to be fragile at intermediate temperatures (less than $800{ }^{\circ} \mathrm{C}$ ), where the multicomponent solid solutions stabilized by high configurational entropy may break down by local chemical disturbance at dislocations and grain boundaries [48-50]. For example, Otto et al. [50] performed annealing experiments on $\mathrm{CoCrFeMnNi}$ at intermediate temperatures $\left(500{ }^{\circ} \mathrm{C}\right.$ and $\left.700{ }^{\circ} \mathrm{C}\right)$ for long durations (500 days) and found formation of NiMn-, FeCo- and Cr-enriched phases, depending upon time and temperature. Similar observation of decomposition was also reported in combination with deformation, however after shorter anneal durations [48-51]. For instance, Schuh et al. [48] detected phase decomposition including formation of $\mathrm{Cr}-, \mathrm{FeCo}-$ and NiMn-enriched phases, after annealing highpressure torsioned $\mathrm{CoCrFeMnNi}$ at $450{ }^{\circ} \mathrm{C}$ for shorter durations (5 minutes to 15 hours). This phase decomposition was assisted by the presence of large number of grain boundaries serving as fast diffusion pathways and preferential nucleation sites for the formation of secondary phases [48]. Furthermore, Tsai et al. [52] investigated the magnitude of the diffusion coefficients of the individual elements in the CoCrFeMnNi HEA and found similar ordering of the diffusion coefficients as that of the pure metals [53]. 
The elements that diffuses fastest at a fixed temperature are reported to be $\mathrm{Mn}$ and $\mathrm{Cr}$, which is consistent with the formation of the $\mathrm{MnNi}$ - and $\mathrm{Cr}$-enriched phases.

In present study, no segregation was observed in the undeformed recrystallized microstructure which was obtained by annealing cold-worked material at $800{ }^{\circ} \mathrm{C}$ for $1 \mathrm{~h}$. This is in agreement with Schuh et al. [48] results, where annealing of the decomposed four-phased HEA matrix, containing NiMn, Cr, and FeCo precipitates, at $800{ }^{\circ} \mathrm{C}$ for $1 \mathrm{~h}$, again led to the single-phase solid solution (i.e., all the precipitates dissolved back into the HEA matrix). Together, with these results it is reconfirmed that the FCC $\mathrm{CoCrFeMnNi}$ solid solution state is stable above approximately $800{ }^{\circ} \mathrm{C}$ and that at lower temperatures several different precipitates form depending on time and temperature. Nevertheless, the effect of cyclic straining, i.e. if deformation provides additional driving force for precipitation (faster precipitation kinetics), still needs to be investigated. Besides, these newly formed secondary phases upon attaining a critical size could not only lower the strength of material (by reducing solid solution strengthening; thus, leading to minor cyclic softening under lower strain amplitudes) but could also cause grain boundary embrittlement due to strain incompatibility with the matrix [48]. This will cause an adverse effect on the $\mathrm{CoCrFeMnNi}$ fatigue life by not only initiating cracks at specimen surface but also assisting their propagation in an intergranular fashion. Independently, coarser $\mathrm{Cr}-\mathrm{O}$ particles that are present in the initial undeformed microstructure also appear to have initiated cracks and affected their propagation (see Fig. 10c, e). Therefore, by choosing composition that eradicate segregation and by improving processing strategies that eliminate impurities such as $\mathrm{Cr}-\mathrm{O}$, high-temperature fatigue properties of HEA can be further enhanced.

\subsection{Serrated flow}

As seen in Fig. 2, serrated flow occurred during LCF of the investigated CoCrFeMnNi HEA. This phenomenon has been widely reported for quasistatic deformation in various alloys [19, 21, 31, 36, 54-57], including the present HEA [6, 49, 58, 59], and also others such as A10.3CoCrFeNi [60], Al0.1CoCrFeNi [61] and Al0.5CoCrCuFeNi [62, 63]. In general, the occurrence of serrated flow can be explained in terms of dynamic strain aging (DSA). McCormick [64] proposed that when mobile dislocations are arrested by a forest dislocation, solute atoms will diffuse to these arrested dislocations, leading to an increase in flow stress by impeding their movement. Once the flow stress reaches a critical value, the arrested dislocations can escape solute atmosphere. At this instance, a comparatively lower stress is required to move dislocations until they are locked again by the next forest dislocation [64, 65]. In DSA, the competition between solute mobility and the dislocation velocity plays a crucial role [9, 30]. DSA in steels has been attributed to the strong interactions between mobile planar dislocations and solute atoms, such as 
interstitial $\mathrm{C}$ or $\mathrm{N}$ atoms at lower temperatures $\left(250{ }^{\circ} \mathrm{C}-450{ }^{\circ} \mathrm{C}\right)$, or substitutional $\mathrm{Cr}$ atoms at higher temperatures $\left(450^{\circ} \mathrm{C}-650{ }^{\circ} \mathrm{C}\right)$ due to different activation energy $[54,55]$.

The major uncertainty in the case of HEAs has been the unclear understanding of the elements that can be considered as solute atoms to impede mobile dislocations [61]. He et al. [49] proposed that it is the diffusion of one of the constituent elements which acts as the solute atom that controls the drag of gliding dislocations and the deformation rate at lower strain rate. For Al0.3CoCrFeNi HEA, Yasuda et al. [60] showed that the solute atmosphere of $\mathrm{Al}$ atoms around moving dislocations or stacking faults is closely related to the DSA. For CoCrFeMnNi, DSA related serrations are reported to have occurred at both cryogenic temperature $(4.2 \mathrm{~K} / 8 \mathrm{~K})[7,8]$ and elevated temperature range $\left(300{ }^{\circ} \mathrm{C}\right.$ to $\left.620{ }^{\circ} \mathrm{C}\right)[58,59]$. Wu et al. [58] and Carroll et al. [59] performed systematic studies using different compositional subsets of $\mathrm{CoCrFeMnNi} \mathrm{HEA}$. They reported the appearance of high temperature serrations in NiCoCr, NiCoMn, $\mathrm{NiCoFe}, \mathrm{NiFeMn}, \mathrm{NiCoFeMn}$ and $\mathrm{NiCoFeCr}$ alloys but not in pure $\mathrm{Ni}$ and its binary subsets (FeNi and $\mathrm{NiCo})$ during tensile straining at $400{ }^{\circ} \mathrm{C}[58,59]$. Therefore, it appears that it is not one specific element, but different elements or their combined synergistic effect that leads to serrations in CoCrFeMnNi HEA and its subsets. Indeed, the formation of $\mathrm{Cr}$ - and $\mathrm{MnNi}$-enriched phases could be taken as an evidence that $\mathrm{Cr}, \mathrm{Mn}$ and $\mathrm{Ni}$ are the possible responsible elements for serrated flow in $\mathrm{CoCrFeMnNi} \mathrm{HEA}$ at $550{ }^{\circ} \mathrm{C}$.

In our study, mobile planar dislocations appear to have undergone jerky motion (see Fig. 7). This is a consequence of the locking and unlocking of the dislocations from the solute atoms during initial cycling, leading to an increase and decrease in flow stress, respectively. Upon further cycling, as the dislocations multiply and interact they tend to get arrested more. This virtually reduces dislocation-solute interactions; hence, gradually leading to a decrease in serration amplitude to zero. Serrations are generally shown to have detrimental effect on fatigue life of the materials. For instance, DSA in NIMONIC PE-16 superalloy increased the strain localization in the planar slip bands, and their impingement at grain-boundary caused internal cracking; thereby, reducing fatigue life [56]. Moreover, DSA in 316L austenitic stainless steel is also known to reduce fatigue life, by enhancing crack initiation sites and accelerating its propagation [57]. However, from the present investigations, the serration's role on the CoCrFeMnNi HEA fatigue life is still unclear and needs further investigations.

\section{Summary and conclusions}

In this work, LCF behavior of an equiatomic CoCrFeMnNi HEA was investigated under different strain amplitudes at $550{ }^{\circ} \mathrm{C}$. The following conclusions can be drawn out of the present investigation: 
1) The cyclic stress response of $\mathrm{CoCrFeMnNi} H E A$ shows three distinct stages that include initial cyclic hardening followed by a quasi-stable cyclic response and finally crack initiation and growth stage. The extent of these stages is a function of applied strain amplitude. For example, the rate and the amount of cyclic hardening increased with increase in applied strain amplitude.

2) In the LCF regime, the CoCrFeMnNi HEA fatigue lives can be accurately described by using the well-known Coffin-Manson law. Compared to common FCC stainless steels, CoCrFeMnNi HEA shows comparable strength and improved LCF lifetimes for similar testing conditions. This is probably due to its small grain size, low SFE and rougher slip planes which inhibited strain localization.

3) Microstructural investigations were carried out to understand deformation mechanisms and their relation with the measured cyclic stress response. The overall texture, grain size and annealing twin density remained stable after cycling CoCrFeMnNi HEA. However, the main difference was observed with respect to the increment in dislocation density. During initial cycling, dislocation multiplication and dislocation-dislocation as well as dislocation-solute atom interaction, contributes to the observed initial cyclic hardening. Dislocation density increased and became more uniform with increase in applied strain amplitude, which is related to the increase in the amount of cyclic hardening. Upon further cycling, equilibrium between dislocations concurrent multiplication and annihilation resulted in a dynamic equilibrium, i.e. a quasi-stable density which is associated with the quasi-stable cycle response. Various distinct dislocation structures such as pile-ups, planar slip bands, dislocation loops and entanglements were observed at lower strain amplitudes. By contrast, heterogeneous dislocation structures including ill-defined cell walls and LAGBs were observed at higher strain amplitudes.

4) The serrated flow in the stress response is due to the interaction between mobile planar dislocations and diffusing solute atoms. Interestingly, chemical instability or segregation in the form of $\mathrm{Cr}$ - and NiMn-enriched secondary phases was observed near grain boundaries upon cyclic straining. The formation of these phases could be taken as an evidence that $\mathrm{Cr}, \mathrm{Mn}$ and $\mathrm{Ni}$ are the possible responsible elements for serrated flow in CoCrFeMnNi HEA at $550{ }^{\circ} \mathrm{C}$.

5) Fatigue cracks initiated at the specimen surface, probably at the $\mathrm{Cr}-\mathrm{O}$ particles that were present in the initial undeformed microstructure or at the coinciding grain boundaries where $\mathrm{Cr}$ - and NiMn-enriched secondary phases nucleated. These cracks propagated predominantly in a transgranular manner by creating ductile fracture features called striations. Furthermore, secondary cracks and Cr-O particles were observed on the fracture surface, which appears to have influenced the main-crack path. Both 
crack initiation and propagation are also assisted by in-situ oxidation that occurred during testing. Nevertheless, by choosing composition that eradicates segregation and by improving processing strategies that eliminate impurities such as $\mathrm{Cr}-\mathrm{O}$, high-temperature fatigue properties of HEA can be further enhanced.

\section{Acknowledgment}

AK and AST gratefully acknowledge financial support by the Deutsche Forschungsgemeinschaft within the framework of the Priority Program "Compositionally Complex Alloys - High-Entropy Alloys (CCAHEA)" (SPP 2006), grants no. KA 4631/1-1.

\section{Data Availability}

The raw/processed data required to reproduce these findings cannot be shared at this time as the data also forms part of an ongoing study.

\section{References}

[1] Y.F. Ye, Q. Wang, J. Lu, C.T. Liu, Y. Yang, High-entropy alloy: challenges and prospects, Materials Today 19(6) (2016) 349-362.

[2] B. Cantor, I.T.H. Chang, P. Knight, A.J.B. Vincent, Microstructural development in equiatomic multicomponent alloys, Materials Science and Engineering: A 375-377 (2004) 213-218.

[3] E.P. George, D. Raabe, R.O. Ritchie, High-entropy alloys, Nature Reviews Materials (2019).

[4] D.B. Miracle, O.N. Senkov, A critical review of high entropy alloys and related concepts, Acta Materialia 122 (2017) 448-511.

[5] B. Gludovatz, A. Hohenwarter, D. Catoor, E.H. Chang, E.P. George, R.O. Ritchie, A fractureresistant high-entropy alloy for cryogenic applications, Science 345(6201) (2014) 1153-1158.

[6] F. Otto, A. Dlouhý, C. Somsen, H. Bei, G. Eggeler, E.P. George, The influences of temperature and microstructure on the tensile properties of a CoCrFeMnNi high-entropy alloy, Acta Materialia 61(15) (2013) 5743-5755.

[7] A.S. Tirunilai, J. Sas, K.-P. Weiss, H. Chen, D.V. Szabó, S. Schlabach, S. Haas, D. Geissler, J. Freudenberger, M. Heilmaier, A. Kauffmann, Peculiarities of deformation of CoCrFeMnNi at cryogenic temperatures, Journal of Materials Research 33(19) (2018) 3287-3300.

[8] A.S. Tirunilai, T. Hanemann, C. Reinhart, V. Tschan, K.P. Weiss, G. Laplanche, J. Freudenberger, M. Heilmaier, A. Kauffmann, Comparison of cryogenic deformation of the concentrated solid solutions CoCrFeMnNi, CoCrNi and CoNi, Materials Science and Engineering: A (2020). 
[9] Y.B. Kang, S.H. Shim, K.H. Lee, S.I. Hong, Dislocation creep behavior of CoCrFeMnNi high entropy alloy at intermediate temperatures, Materials Research Letters 6(12) (2018) 689-695.

[10] H.T. Jeong, H.K. Park, K. Park, T.W. Na, W.J. Kim, High-temperature deformation mechanisms and processing maps of equiatomic CoCrFeMnNi high-entropy alloy, Materials Science and Engineering: A 756 (2019) 528-537.

[11] T. Niendorf, T. Wegener, Z. Li, D. Raabe, Unexpected cyclic stress-strain response of dualphase high-entropy alloys induced by partial reversibility of deformation, Scripta Materialia 143 (2018) 63-67.

[12] F. Bahadur, K. Biswas, N.P. Gurao, Micro-mechanisms of Microstructural Damage due to Low Cycle Fatigue in CoCuFeMnNi High Entropy Alloy, International Journal of Fatigue (2019).

[13] A.G. Wang, X.H. An, J. Gu, X.G. Wang, L.L. Li, W.L. Li, M. Song, Q.Q. Duan, Z.F. Zhang, X.Z. Liao, Effect of grain size on fatigue cracking at twin boundaries in a CoCrFeMnNi highentropy alloy, Journal of Materials Science \& Technology (2019).

[14] K.V.S. Thurston, B. Gludovatz, A. Hohenwarter, G. Laplanche, E.P. George, R.O. Ritchie, Effect of temperature on the fatigue-crack growth behavior of the high-entropy alloy CrMnFeCoNi, Intermetallics 88 (2017) 65-72.

[15] Y.-K. Kim, G.-S. Ham, H.S. Kim, K.-A. Lee, High-cycle fatigue and tensile deformation behaviors of coarse-grained equiatomic CoCrFeMnNi high entropy alloy and unexpected hardening behavior during cyclic loading, Intermetallics 111 (2019).

[16] Z. Chlup, S. Fintová, H. Hadraba, I. Kuběna, M. Vilémová, J. Matějíček, Fatigue Behaviour and Crack Initiation in CoCrFeNiMn High-Entropy Alloy Processed by Powder Metallurgy, Metals 9(10) (2019).

[17] Y.Z. Tian, S.J. Sun, H.R. Lin, Z.F. Zhang, Fatigue behavior of CoCrFeMnNi high-entropy alloy under fully reversed cyclic deformation, Journal of Materials Science \& Technology 35(3) (2019) 334-340.

[18] J. Morrow, Cyclic plastic strain energy and fatigue of metals, Internal friction, damping, and cyclic plasticity, ASTM International1965.

[19] R. Sandhya, K.B.S. Rao, S. Mannan, R. Devanathan, Substructural recovery in a cold worked Ti-modified austenitic stainless steel during high temperature low cycle fatigue, International journal of fatigue 23(9) (2001) 789-797.

[20] K.B.S. Rao, M. Valsan, R. Sandhya, S. Mannan, P. Rodriguez, An assessment of cold work effects on strain-controlled low-cycle fatigue behavior of type 304 stainless steel, Metallurgical Transactions A 24(4) (1993) 913-924.

[21] S.K. Krovvidi, S. Goyal, A. Bhaduri, Low cycle fatigue and creep-fatigue response of the 316Ti stainless steel, Frattura ed Integrità Strutturale 13(48) (2019) 577-584.

[22] S. Suresh, Fatigue of materials, (1998). 
[23] S.S. Manson, Behavior of materials under conditions of thermal stress, National Advisory Committee for Aeronautics1953.

[24] L.F. Coffin Jr, A study of the effects of cyclic thermal stresses on a ductile metal, Transactions of the American Society of Mechanical Engineers, New York 76 (1954) 931-950.

[25] N.L. Okamoto, S. Fujimoto, Y. Kambara, M. Kawamura, Z.M. Chen, H. Matsunoshita, K. Tanaka, H. Inui, E.P. George, Size effect, critical resolved shear stress, stacking fault energy, and solid solution strengthening in the CrMnFeCoNi high-entropy alloy, Sci Rep 6 (2016) 35863.

[26] M. Calcagnotto, D. Ponge, E. Demir, D. Raabe, Orientation gradients and geometrically necessary dislocations in ultrafine grained dual-phase steels studied by 2D and 3D EBSD, Materials Science and Engineering: A 527(10-11) (2010) 2738-2746.

[27] A. Chauhan, L. Straßberger, U. Führer, D. Litvinov, J. Aktaa, Creep-fatigue interaction in a bimodal 12Cr-ODS steel, International Journal of Fatigue 102 (2017) 92-111.

[28] A. Chauhan, J. Hoffmann, D. Litvinov, J. Aktaa, High-temperature low-cycle fatigue behavior of a 9Cr-ODS steel: Part 2 - hold time influence, microstructural evolution and damage characteristics, Materials Science and Engineering: A 730 (2018) 197-206.

[29] A. Chauhan, J. Hoffmann, D. Litvinov, J. Aktaa, High-temperature low-cycle fatigue behavior of a 9Cr-ODS steel: Part 1 - pure fatigue, microstructure evolution and damage characteristics, Materials Science and Engineering: A 707 (2017) 207-220.

[30] S. Huang, W. Li, S. Lu, F. Tian, J. Shen, E. Holmström, L. Vitos, Temperature dependent stacking fault energy of FeCrCoNiMn high entropy alloy, Scripta Materialia 108 (2015) 44-47.

[31] S. Goyal, S. Mandal, P. Parameswaran, R. Sandhya, C.N. Athreya, K. Laha, A comparative assessment of fatigue deformation behavior of $316 \mathrm{LN} \mathrm{SS}$ at ambient and high temperature, Materials Science and Engineering: A 696 (2017) 407-415.

[32] V. Srinivasan, R. Sandhya, M. Valsan, K.B.S. Rao, S. Mannan, Comparative evaluation of strain controlled low cycle fatigue behaviour of solution annealed and prior cold worked $316 \mathrm{~L}(\mathrm{~N})$ stainless steel, International journal of fatigue 26(12) (2004) 1295-1302.

[33] G.P. Reddy, R. Sandhya, S. Sankaran, M. Mathew, Low cycle fatigue behavior of 316LN stainless steel alloyed with varying nitrogen content. part I: cyclic deformation behavior, Metallurgical and Materials Transactions A 45(11) (2014) 5044-5056.

[34] M.S. Pham, C. Solenthaler, K.G.F. Janssens, S.R. Holdsworth, Dislocation structure evolution and its effects on cyclic deformation response of AISI 316 L stainless steel, Materials Science and Engineering: A 528(7-8) (2011) 3261-3269.

[35] A. Chauhan, D. Litvinov, T. Gräning, J. Aktaa, High-temperature low-cycle fatigue behavior and microstructural evolution of an improved austenitic ODS steel, Journal of Materials Research 33(12) (2018) 1814-1821.

[36] M.S. Pham, S.R. Holdsworth, Dynamic strain ageing of AISI 316L during cyclic loading at $300^{\circ} \mathrm{C}$ : Mechanism, evolution, and its effects, Materials Science and Engineering: A 556 (2012) 122-133. 
[37] J. Nellessen, S. Sandlöbes, D. Raabe, Effects of strain amplitude, cycle number and orientation on low cycle fatigue microstructures in austenitic stainless steel studied by electron channelling contrast imaging, Acta Materialia 87 (2015) 86-99.

[38] Y. Li, C. Laird, Cyclic response and dislocation structures of AISI 316L stainless steel. Part 1: single crystals fatigued at intermediate strain amplitude, Materials Science and Engineering: A 186(1-2) (1994) 65-86.

[39] P. Li, S. Li, Z. Wang, Z. Zhang, Fundamental factors on formation mechanism of dislocation arrangements in cyclically deformed fcc single crystals, Progress in Materials Science 56(3) (2011) 328-377.

[40] D. Hull, D.J. Bacon, Introduction to dislocations, 2001.

[41] T. Mayama, K. Sasaki, M. Kuroda, Quantitative evaluations for strain amplitude dependent organization of dislocation structures due to cyclic plasticity in austenitic stainless steel $316 \mathrm{~L}$, Acta Materialia 56(12) (2008) 2735-2743.

[42] D. Ye, S. Matsuoka, N. Nagashima, N. Suzuki, Multi-scale deformation behavior investigation of $18 \mathrm{Cr}-8 \mathrm{Ni}$ austenitic steel subjected to low-cycle fatigue loading, Materials characterization 55(2) (2005) 106-117.

[43] M.S. Pham, S.R. Holdsworth, K.G.F. Janssens, E. Mazza, Cyclic deformation response of AISI 316L at room temperature: Mechanical behaviour, microstructural evolution, physicallybased evolutionary constitutive modelling, International Journal of Plasticity 47 (2013) 143-164.

[44] E. Thiele, C. Holste, R. Klemm, Influence of size effect on microstructural changes in cyclically deformed polycrystalline nickel, Zeitschrift Fur Metallkunde 93(7) (2002) 730-736.

[45] J. Man, K. Obrtlík, J. Polák, Extrusions and intrusions in fatigued metals. Part 1. State of the art and history, Philosophical Magazine 89(16) (2009) 1295-1336.

[46] K. Yamaguchi, K. Kanazawa, Influence of grain size on the low-cycle fatigue lives of austenitic stainless steels at high temperatures, Metallurgical Transactions A 11(10) (1980) 1691-1699.

[47] S. Lee, M.J. Duarte, M. Feuerbacher, R. Soler, C. Kirchlechner, C.H. Liebscher, S.H. Oh, G. Dehm, Dislocation plasticity in FeCoCrMnNi high-entropy alloy: quantitative insights from in situ transmission electron microscopy deformation, Materials Research Letters 8(6) (2020) 216-224.

[48] B. Schuh, F. Mendez-Martin, B. Völker, E.P. George, H. Clemens, R. Pippan, A. Hohenwarter, Mechanical properties, microstructure and thermal stability of a nanocrystalline CoCrFeMnNi high-entropy alloy after severe plastic deformation, Acta Materialia 96 (2015) 258268.

[49] J.Y. He, C. Zhu, D.Q. Zhou, W.H. Liu, T.G. Nieh, Z.P. Lu, Steady state flow of the FeCoNiCrMn high entropy alloy at elevated temperatures, Intermetallics 55 (2014) 9-14.

[50] F. Otto, A. Dlouhý, K.G. Pradeep, M. Kuběnová, D. Raabe, G. Eggeler, E.P. George, Decomposition of the single-phase high-entropy alloy CrMnFeCoNi after prolonged anneals at intermediate temperatures, Acta Materialia 112 (2016) 40-52. 
[51] W. Zhou, L.M. Fu, P. Liu, X.D. Xu, B. Chen, G.Z. Zhu, X.D. Wang, A.D. Shan, M.W. Chen, Deformation stimulated precipitation of a single-phase CoCrFeMnNi high entropy alloy, Intermetallics 85 (2017) 90-97.

[52] K.Y. Tsai, M.H. Tsai, J.W. Yeh, Sluggish diffusion in Co-Cr-Fe-Mn-Ni high-entropy alloys, Acta Materialia 61(13) (2013) 4887-4897.

[53] G. Neumann, C. Tuijn, Self-diffusion and impurity diffusion in pure metals: handbook of experimental data, Elsevier2011.

[54] S. Hong, K. Lee, S. Lee, Dynamic strain aging effect on the fatigue resistance of type 316L stainless steel, International Journal of Fatigue 27(10-12) (2005) 1420-1424.

[55] H. Zhou, Y. He, M. Cui, Y. Cen, J. Jiang, Dependence of dynamic strain ageing on strain amplitudes during the low-cycle fatigue of TP347H austenitic stainless steel at $550^{\circ} \mathrm{C}$, International Journal of Fatigue 56 (2013) 1-7.

[56] M. Valsan, D. Sastry, K.B. Sankara Rao, S. Mannan, Effect of strain rate on the hightemperature low-cycle fatigue properties of a nimonic PE-16 superalloy, Metallurgical and materials transactions a 25(1) (1994) 159-171.

[57] S. Hong, The tensile and low-cycle fatigue behavior of cold worked 316L stainless steel: influence of dynamic strain aging, International Journal of Fatigue 26(8) (2004) 899-910.

[58] Z. Wu, H. Bei, G.M. Pharr, E.P. George, Temperature dependence of the mechanical properties of equiatomic solid solution alloys with face-centered cubic crystal structures, Acta Materialia 81 (2014) 428-441.

[59] R. Carroll, C. Lee, C.W. Tsai, J.W. Yeh, J. Antonaglia, B.A. Brinkman, M. LeBlanc, X. Xie, S. Chen, P.K. Liaw, K.A. Dahmen, Experiments and Model for Serration Statistics in Low-Entropy, Medium-Entropy, and High-Entropy Alloys, Sci Rep 5 (2015) 16997.

[60] H.Y. Yasuda, K. Shigeno, T. Nagase, Dynamic strain aging of Al 0.3 CoCrFeNi high entropy alloy single crystals, Scripta Materialia 108 (2015) 80-83.

[61] M. Komarasamy, K. Alagarsamy, R.S. Mishra, Serration behavior and negative strain rate sensitivity of Al0.1CoCrFeNi high entropy alloy, Intermetallics 84 (2017) 20-24.

[62] S. Chen, X. Xie, B. Chen, J. Qiao, Y. Zhang, Y. Ren, K.A. Dahmen, P.K. Liaw, Effects of Temperature on Serrated Flows of Al0.5CoCrCuFeNi High-Entropy Alloy, Jom 67(10) (2015) 2314-2320.

[63] S. Chen, X. Xie, W. Li, R. Feng, B. Chen, J. Qiao, Y. Ren, Y. Zhang, K.A. Dahmen, P.K. Liaw, Temperature effects on the serrated behavior of an Al0.5CoCrCuFeNi high-entropy alloy, Materials Chemistry and Physics 210 (2018) 20-28.

[64] P. McCormigk, A model for the Portevin-Le Chatelier effect in substitutional alloys, Acta Metallurgica 20(3) (1972) 351-354.

[65] A.H. Cottrell, D. Dexter, Dislocations and plastic flow in crystals, American journal of physics 22 (1954) 242-243. 